\title{
Developing a Pedagogical Framework for Designing a Multisensory Serious Gaming Environment
}

\author{
Sara Price \\ UCL Knowledge Lab \\ University College London \\ Institute of Education \\ London, UK \\ sara.price@ucl.ac.uk
}

\author{
Sam Duffy \\ UCL Knowledge Lab \\ University College London \\ Institute of Education \\ London, UK \\ sam.duffy@ucl.ac.uk
}

\author{
Monica Gori \\ Robotics Brain and Cognitive Sciences \\ Istituto Italiano di Tecnologia \\ Genoa, Italy \\ Monica.Gori@iit.it
}

\begin{abstract}
The importance of multisensory interaction for learning has increased with improved understanding of children's sensory development, and a flourishing interest in embodied cognition. The potential to foster new forms of multisensory interaction through various sensor, mobile and haptic technologies is promising in providing new ways for young children to engage with key mathematical concepts. However, designing effective learning environments for real world classrooms is challenging, and requires a pedagogically, rather than technologically, driven approach to design. This paper describes initial work underpinning the development of a pedagogical framework, intended to inform the design of a multisensory serious gaming environment. It identifies the theoretical basis of the framework, illustrates how this informs teaching strategies, and outlines key technology research driven perspectives and considerations important for informing design. An initial table mapping mathematical concepts to design, a framework of considerations for design, and a process model of how the framework will continue to be developed across the design process are provided.
\end{abstract}

\section{CCS CONCEPTS}

- Applied computing $\rightarrow$ Education $\rightarrow$ Interactive learning environments - Human-centered computing $\rightarrow$ HCI theory, concepts and models - Social and professional topics $\rightarrow$ User Characteristics $\rightarrow$ Age $\rightarrow$ Children

\section{KEYWORDS}

Interaction design, Education, Participatory design, Ubiquitous and mobile computing.

Permission to make digital or hard copies of all or part of this work for personal or classroom use is granted without fee provided that copies are not made or distributed for profit or commercial advantage and that copies bear this notice and the full citation on the first page. Copyrights for components of this work owned by others than ACM must be honored. Abstracting with credit is permitted. To copy otherwise, or republish, to post on servers or to redistribute to lists, requires prior specific permission and/or a fee. Request permissions from Permissions@acm.org.

1st ACM SIGCHI International Workshop on Multimodal Interaction, November 13, 2017, Glasgow, United Kingdom (C) 2017 Association for Computing Machinery. ACM ISBN 978-1-4503-5557-5/17/11 ..\$15.00 https://doi.org/10.1145/3139513.3139517
ACM Reference format:

S. Price, S. Duffy and M. Gori. 2017. In Proceedings of 1st ACM SIGCHI International Workshop on Multimodal Interaction, Glasgow, UK, November 2017 (MIE'2017), 8 pages.

https://doi.org/10.1145/3139513.3139517

\section{INTRODUCTION}

The past two decades have seen an increasing exploration into the use of technology for supporting teaching and learning, with a recent emphasis on multimodal and multisensory interaction. This has coincided with technological progress and development, which has expanded the potential to exploit sensory forms of engagement within learning. Alongside this, renewed interest in embodied cognition and interaction emphasises the role of experience, the sensory body, emotion and social interaction for cognition and learning. The use of sensory modalities to teach elementary school children also derives from renewed neuroscientific understanding about how sensory modalities interact and are integrated during development. Teaching and learning practices should reflect this scientific evidence, by introducing novel pedagogical methodologies grounded upon it. In particular, these perspectives support an embodied and enactive pedagogical approach, using different sensory-motor feedback (audio, haptic, and visual) to teach concepts to primary school children. Since the use of movement has been shown to deepen and strengthen learning, retention, and engagement [25, 38], an embodied and enactive approach would be more intuitive, being based on the experience of, and perceptual responses to, motor acts.

Critiques of technology-driven approaches to design and development of novel digital learning environments suggest that the design should instead be pedagogically driven: that the affordances of the technology should be mapped to pedagogical principles. This has implications for both the methodology and the development of a pedagogical framework.

WeDraw (http://www.wedraw.eu) is a two-year project which aims to mediate the teaching of primary school mathematical concepts, such as geometry and arithmetic, through the design, development and evaluation of multisensory serious games, using a combination of sensory interactive technologies. This approach will integrate visual, sound and haptic feedback, in response to whole body movement. In so doing it aims to enable children to better, or differently, engage with challenging concepts, allowing them to explore in ways that lead to new forms of thinking. 
Furthermore, it offers new opportunities for visually impaired children through the provision of additional stimuli [19].

Methodologically we are taking a design based research approach, employing participatory design techniques in an iterative design process, working closely with teachers. To date participatory design workshops have been used to support teachers in identifying key challenging mathematical concepts for children aged 6-10, and developing initial design ideas that foreground multisensory forms of interaction. Lesson observations are used to identify key considerations for the successful embedding of the games in the classroom, and determining how they can support and compliment the teaching activity that is already taking place.

Pedagogical considerations are defined by drawing on relevant theoretical approaches to teaching and learning, and technology design approaches that supporting learning (for example, from serious games and digitally augmented environments research). Digital environments, and learning activities need to deliver more than just an enjoyable experience: each game-based activity, and use of specific modalities, must reinforce an aspect of the mathematical concept being explored, and be integrated with the expectations of schools, parents and teachers, as defined by the school curriculum. This paper describes how we have developed a preliminary pedagogical framework, intended to inform the design of a multisensory serious gaming environment for the WeDraw project.

\section{PEDAGOGY DRIVEN DESIGN}

Pedagogy underpins teaching and learning approaches. There are different pedagogies, which generate different kinds of teaching strategies, but what is important is choosing appropriate pedagogies for a specific time and place [60] and audience. The key consideration is achieving pedagogically driven design rather than technologically driven design. In this way, the design "can be informed both by pedagogical theories and experiences from educational practice" [p.431, 39].

Little work has been done to date to formally develop pedagogical frameworks in order to inform the design and development of digital learning environments [39]. Starr-Glass [67] describes a pedagogical framework as "the integrated set of philosophical considerations, teaching preferences, and learning values that informs and motivates the instructor in designing and facilitating a learning experience". These considerations are transformed into strategies or approaches for achieving specific educational outcomes. To inform digital design, the framework also needs to take into account the technological affordances in relation to pedagogy and learning design guidelines emerging from research literature.

A variety of approaches have been used to apply key pedagogical principles to design. Laanpere et al [39] propose a conceptual and process model, focusing on four contemporary notions of learning: self-directed learning (fostering interaction and linking to interface design /usability); competence-based learning; collaborative knowledge building; and task-centered instructional design (situating in an authentic context with problem based activity). Radcliffe [56] advocates the use of a set of guiding questions, for example, "What type(s) of learning and teaching are we trying to foster and why? Why is this likely to make a difference to learning? What is the theory and evidence?" Other approaches draw on notions of 'affordance', both technological and pedagogical, combined with theory to identify pedagogical principles and underpin the pedagogical framework (for example see $[39,50]$ ).

\section{THEORETICAL ASSUMPTIONS FOR MULTISENSORY LEARNING}

Instructional technology environments are grounded in epistemological frameworks considered to be effective for teaching and learning. Psychologists and philosophers have long argued for the role of sensori-motor interaction with the world in cognitive development $[12,45,51,69]$. Recent changes in thinking across other disciplines further emphasise the role of embodiment in cognition, including neuroscience [16, 21], Artificial Intelligence [4], Human Computer Interaction [18, 73], linguistics [40], and gesture studies [22]. There is increasing evidence that sensori-motor experience and interaction with the environment are central to meaning making and conceptual understanding $[5,7,62,66,72]$, and provide the basis for learning.

Research shows that during the first years of life, sensory modalities communicate with each other, and the absence of one sensory input impacts the development of others [23]. According to cross-sensory calibration theory, in children under 8-10 years, the most robust sensory modality calibrates the others [24]. This suggests that some sensory modalities are more suitable than others to convey specific information, and hence to teach specific concepts. For example, children use the tactile modality to perceive the size of objects and the visual to perceive their orientation. Recent findings show that children start to integrate multisensory information only after 8-10 years of age [15]. There is substantial evidence that mathematical cognition is embodied $[33,40]$, since it is grounded in the physical environment, and based on perception and action [3]. These perspectives highlight the importance of multi-sensory, situated, experiential and discovery forms of learning.

Several studies show the benefits of embodied learning approaches in primary mathematics (for example, [22, 42]). Lakoff \& Nunez [40] propose that mathematical concepts are grounded upon bodily experiences, such as manipulation of collections of objects, or physical movement in a linear path that link to ideas of grouping and number line. Educational research in mathematics has reported ways in which 'action' plays a role in teaching and learning $[1,3,22,47]$. A central component of this is 'enactment'. Barsalou [7] highlights the importance of re-enaction of modality specific experiences: "Just as thinking about (or recognizing) a cup might involve sensorimotor preparation for grasping or drinking, thinking about an equilateral triangle might involve covertly re-enacting modality-specific experiences of physical measurement or the construction of geometric objects" [p.210,7].

Similarly, gestures and simulated actions provide evidence of mathematical reasoning [31]. Fostering specific actions that relate to the gestures of those who correctly explain a mathematics problem helps children to learn mathematics [22]. While 'actions' benefit from being accurate, they also need to be congruent, and through this, become meaningful in relation to the concept being 
learned [35, 39]. Wiemers et al. [71] showed that participants performing mental arithmetic tasks involving addition and subtraction, solved more problems when their upward and downward movements or movements to right and left were congruent with magnitude than when incongruent.

Similar effects of action and gesture have been shown for learning geometry [20, 37]. However, Walkington et al. [70] report greater transfer of knowledge to new problems when using full-body gestures compared to only hand gestures, arguing that full-body gestures better highlight how the actions relate to the relevant concepts and constraints. Similarly, second and third grade children learning about angles through mindful movements outperformed those learning verbally [63]. The movements being performed by the learners allowed for the concepts to be encoded, and their reasoning to be externalised, cementing their learning. Ma [41] highlights two important 'bodily' design features: (i) students' own bodies, "sometimes simultaneously, became mathematical objects (e.g. endpoints of line segments)"; and (ii) their bodily interactions "supported communication and negotiation of mathematical ideas (e.g., mathematical meaning was given to visible and tactile phenomena)" [p.159, 41]. The 'body' therefore serves a dual purpose: representational meaning that is externally visible and accessible to others (e.g. an angle); and a contribution to the phenomena being explored (e.g. triangle/shape).

Three other research findings are worthy of noting. Firstly, it is important to foster reflection around action to effectively support learning $[43,65]$. Secondly, using multiple physical manipulatives and pictures emphasises transference between modalities in order to teach concepts of unit, fraction equivalence and comparison [10]. Thirdly, the need for digital augmentation to go beyond what is possible in the 'real' world, introducing opportunities for collaboration, which fosters improved motivation, learning outcomes and social skills [34].

Drawing on these theoretical perspectives, and associated research to date, we can identify key aspects of embodiment that contribute to our pedagogical considerations:

1. Body-based, sensori-motor experiences

2. Collaborative and multi-user activities (visible body)

3. Use of multisensory and multimodal resources

4. Meaningful gestures, actions and movements in relation to the mathematical concept

\section{TECHNOLOGY DESIGN CONSIDERATIONS}

Physical manipulatives, wearable computing, haptic devices and other sensor-based technologies bring a number of affordances for interaction, and fostering embodied multisensory forms of learning. Physical objects, action and movements placed upon the objects, or bodily movement and gestures enacted freely in space can be embedded with computational power and coupled with digital information. Augmenting objects and action can be realised by flexible linking of interaction to digital information through a variety of modalities, including visual, aural and tactile. This offers new opportunities for learning, e.g. making the invisible visible, the inaudible audible, the implicit explicit, and making salient important aspects of a concept. The notion of digital feedback is linked to digital augmentation in the sense that 'augmentation' is a form of implicit feedback, where the emphasis is on designing explicit feedback to scaffold both interaction and the learning idea.

Location/spatial technologies enable spatial representation of information, and allow users to control information through spatial behaviour [58]. They provide opportunities for design to encourage specific movement in relation to mathematical concepts, e.g. moving forwards or backwards in relation to number line concepts. Tangible and haptic technologies offer new opportunities for augmented simulation, particularly in enabling physical experience through manipulation or experience of force, pressure and kinesthetic interaction. Emergent technologies enable communication to take place between devices, people and actions, enabling designs that foster collaboration, social interactivity, and aggregation, where information across devices is gathered by a central server, and distributed [58].

Many successful computer based tools can aid learning and exploration of mathematical concepts, for example ScratchMaths which combines maths with computational thinking [9] or the dynamic geometry tool GeoGebra [27]. However, they are often designed for a single user and largely based on interaction with a flat screen. While there is a body of work around tangible, whole body interaction and digital games, consideration of serious games is often limited to video games, played on a desktop computer. However, this reduces the affordances available for multisensory learning. Since WeDraw aims to embed a multisensory experience into a strong game narrative, here we outline some key design guidelines derived from contemporary research on serious games and digitally augmented learning environments, that are valuable in informing the design considerations for WeDraw.

\subsection{Serious Games Research}

Games and play are an important part of the social and cognitive development of young children [48]. Consciously designing games that can function as a vehicle for learning 'serious' (i.e. non-game) content can motivate learners in new ways [52]. Serious games fulfil many of the goals of constructivism [11] and there is empirical evidence that they can promote learning in secondary and higher education [32, 44]. Gameplay has been found to yield significant effects on maths performance, promoting test-based cognitive learning achievement [35]. Serious games initiatives which focus on deeper learning in the context of an enjoyable experience are more likely to succeed in their pedagogical aims [58], but a serious game will not succeed just because it has educational content. The game must be engaging and motivating: an idea that is encapsulated by the phenomenological concept of 'flow' [46], which has two main conditions: ( $i$ ) perceived challenges, or opportunities for action, that stretch (neither overmatching nor underutilising) existing skills; and (ii) clear proximal goals and immediate feedback about the progress that is being made. Mapping of perceived challenge and skill identifies three regions of experience; flow being achieved when capabilities and challenge are balanced (Figure 1). Maintaining this balance throughout the gaming experience allows a player to stay in the channel of flow and maintains their 
motivation to keep playing. To achieve this, instructional game designers need to understand how game characteristics, competition and goals, rules, challenges, choices, and fantasy, used in both edutainment and serious games, can influence motivation and facilitate learning.

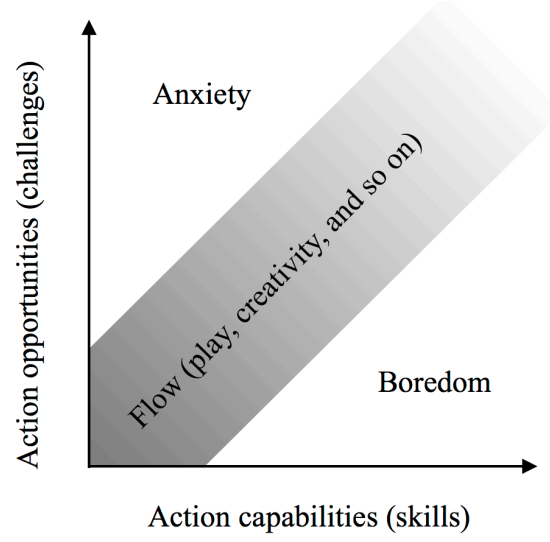

Figure 1. The original model of flow state [46]

Charsky [11] outlines some key considerations for designing a serious game for pedagogy:

1. Goals: game goals should match the learning goals.

2. Rewards: gamers are rewarded with feedback that comes in varying forms and degrees of usefulness, such as new tools, currency, access to new game spaces, people, or levels, or the very typical increase in points.

3. Competition: can be fostered between teams, which encourages collaboration, and has been shown to be effective in promoting positive maths attitudes [35].

4. Duration: longer gameplay periods can provide learners with opportunities to achieve more complex learning goals, but only if motivation is maintained.

5. Rules: constraints that limit the actions a gamer can take outline the boundaries of educational concepts, the rule structure provides practice on a skill set.

6. Choice: the number of options and decisions a gamer has prior to and during game play. Choices can be expressive (to aid motivation), strategic (the gamer's ability to change game attributes such as level of difficulty), or tactical (e.g. the decision to "branch" off from one narrative line to an alternative plot, or to more difficult content).

7. Challenge: the challenges should be designed to fulfil learning goals, whilst maintaining 'flow'.

8. Fantasy: a creative narrative that provides motivating and exciting game play, and cohesion for different levels or modules.

9. Fidelity: using graphics, audio, video, three-dimensional virtual worlds and artificial intelligence to authentically represent reality.

Educational games need to be designed with attention to contemporary learning theories, including customisation of task difficulty to the learner's capabilities, metacognitive reflection on the learning taking place, and consideration of the rich situated interaction among learner, game environment and classroom environment [74]. To succeed in its aims, a serious game must achieve pedagogical aims, social interaction and game characteristics.

\subsection{Digitally Augmented Learning Environments}

A substantial body of interdisciplinary research identifies key design considerations for mobile, tangible and sensor-based learning environments, drawing on both theory and empirical studies, engaging in participatory design processes, and where possible, with end users 'in the wild'. Key considerations include the design of physical-digital couplings, physical location and timing of digital feedback; design of feedback and associated mapping to movement and concept; fostering meaningful interaction, exploration, collaboration and interpretation.

The distance in space between physical and digital components of the system influences attention, interaction and interpretation. In tangible environments, the close coupling of object to digital effect is important in terms of making links between object, action and representation i.e. any information presented alongside physical manipulatives needs to be as close to the physical manipulative as possible, rather than, for example, on a separate piece of paper that needs to be separately attended to $[14,53,55$, 68]. In whole body interaction (WBI), spaces combining visual floor projections simultaneously with wall projections gives rise to conflicts in visual attention demands. Whilst each are instrumental in guiding action, this splits attention, and reduces the ability to make important mappings between action and digital output. However, the use of audio in combination with visual offers a way of focusing attention and can result in better linking of action and effect [59].

In a classroom of children, who only have a finite lesson time, it is important that each child can participate in the activities. Educational research has found that working in pairs or small groups can have beneficial effects on learning and development, particularly in early years and primary education [8], however achieving the conditions for effective group work in the classroom is more difficult. A wall projection of action and events has been shown to be valuable for observers, although it is critical that the experience is made explicit and accessible to observers, in ways that provide the opportunity for co-participation or social interaction [26]. Tangible and WBI environments have been shown to foster collaborative learning, specifically through increased awareness of others' actions [28, 54]. Hornecker and Burr [29] talk about notions of embodied facilitation and spatial interaction, which highlight the design of the space in relation to the interactive devices in shaping social interaction.

A substantial amount of work has looked at information flow: links between action, intention and feedback, primarily in relation to the metaphors or meaning embedded in the actions, objects and digital effects. Hornecker \& Dunser [30] highlight the importance of matching the physical affordances of objects and actions, with the actual capabilities of the digital system, and with users' understanding of the interaction. For example, physical blocks on a tangible tabletop can be tracked on the surface, but not if lifted or set on top of another block. In these contexts, activities need to 
be designed that constrain actions accordingly. Antle [6] highlights three forms of mappings:

1. Perceptual mappings, e.g. between the appearance of physical and digital artefacts and representations;

2. Behavioural mappings, that take into consideration children's understanding of cause-effect relationships, including temporal and spatial contiguity;

3. Semantic mappings, which consider children's understanding of the meaning of their action and associated representations.

Notions of 'metaphor' stem from semantic mappings and are critical since they also underpin abstract learning topics. This suggests the need to carefully consider the metaphor being used in conveying the learning topic, mapping this to the design of the system. Mappings can fall on a continuum between direct and ambiguous, and need to be designed to be 'meaningful' [54]: meaning being strongly influenced by real world and familiar experiences [55]. Mappings deemed as 'persistent' [61] typically form a solid frame for the interaction. Our everyday experiences cannot always provide opportunities to encounter, embody and then rehearse the underlying aspects of mathematical concepts [2]. Crafting specific experiences through the use of physical materials is effective, provided that the physical representation adequately encompasses all conceptual features [13]. For example, in a study of low income pre-schoolers, Siegler and Ramani [64] found that playing a linear numerical board game improved performance in numerical estimation and numerical magnitude, when compared to playing numerical board games that did not correspond to number representation. This highlights the importance of correspondence between representation/action and metaphorical mapping to mathematical concepts.

\section{WEDRAW PEDAGOGICAL FRAMEWORK}

It is important that design scenarios take into account the evolution of mathematical concepts as outlined in the school curriculum. Game content must draw on the issues that are fundamental to understanding children's learning of mathematics [48]. To ensure that children remain sufficiently motivated, and in a state of flow, the challenge must be appropriate to the age of the child for the concept identified. Thus, for WeDraw, the key foundation for the pedagogical framework is the set of mathematical concepts outlined in the Nation Curriculum for 6-10 year olds, and digital activities will be designed around this. Within this, a subset of topics deemed to be most challenging for children to understand, that also seemed to be suitable for exploration through a multisensory game environment, were identified through a series of workshops and questionnaires involving teachers from the UK and Italy [19], supplemented by classroom observations. Further concept specification and desired learning outcomes were drawn from UK Curriculum documents [17] and a Nuffield Foundation report [49], specifically identifying relevant key pedagogical challenges for primary school maths learning.

\subsection{Framework Development}

The initial framework aimed to map specific ideas from the mathematical topics identified, through to design considerations in a table format. For example, see Figure 3, which illustrates this with respect to symmetry. Applying the expectations of the National Curriculum, we see that there are two distinct phases within the age group we are considering. The ability to identify the line of symmetry in simple 2D shapes is an expectation for 6 year olds, when symmetry is introduced in year 2 . However, this is expanded in year 4 , where from the age of 8 children are expected to be able to make the same identification for shapes with different orientations, and be aware that some shapes have more than one line of symmetry. They must be able to complete the mirror reflection for a half a shape (Figure 2). This has implications for a serious game designed to support understanding of symmetry for primary school children, as there is a clear difference between the expectations for 6 year olds compared to 8 year olds. The game needs to allow younger children to explore the concepts at a level where they are comfortable, whilst allowing challenge for children who have started to explore the next phase of symmetry. This is something that technologists and game designers may have less understanding of, but has important implications for game design. For example, indicating where the differences between different levels of difficulty might be set, or whether different versions of the game might be required for different age groups.
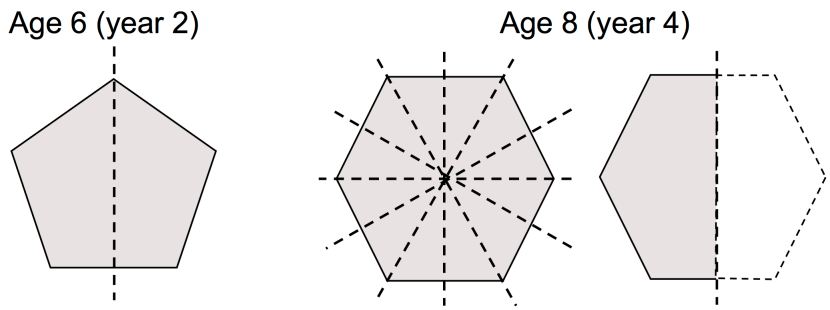

Figure 2. Year based curriculum requirements for comprehension of the concept of symmetry

Whilst this approach taken in Figure 3 was useful, it was felt to be too linear. In conjunction with teaching strategies and mathematical metaphor, the pedagogical design needs to take into consideration the affordances of the technology, and the design considerations derived from recent relevant research. As our thinking progressed, we developed a framework that illustrates the different aspects that are useful in informing the pedagogical affordances and design features that should be applied to each serious game activity, related to a specific mathematical concept (Figure 4). In essence, key teaching and learning strategies are derived from the pedagogical model (drawn from relevant theories of learning); and relevant metaphorical ideas are identified in relation to each mathematical concept, as expressed in the curriculum for the age group being considered. For example, if we are thinking about fractions, then the metaphor of 'partitioning' is considered valuable in conceptualising whole to part ideas. This metaphor can then inform the kinds of bodily actions or gestures to be designed - ones that involve 'partitioning'. If we are thinking about positive and negative numbers in the Cartesian plane, then we need a metaphor for representing and moving between negative and positive numbers, where the negative number is meaningful in itself and not just a product of subtraction. One metaphor for this might be temperature. 


\begin{tabular}{|c|c|c|c|}
\hline $\begin{array}{l}\text { Specific challenges } \\
\text { from teachers }\end{array}$ & Mapping to curriculum/ year group & Pedagogical considerations & Key Design considerations \\
\hline $\begin{array}{l}\text { Symmetry: } \\
\text { Considered easier } \\
\text { for simple shapes } \\
\text { such as circles and } \\
\text { triangles but } \\
\text { challenging once the } \\
\text { shape becomes more } \\
\text { complex. }\end{array}$ & 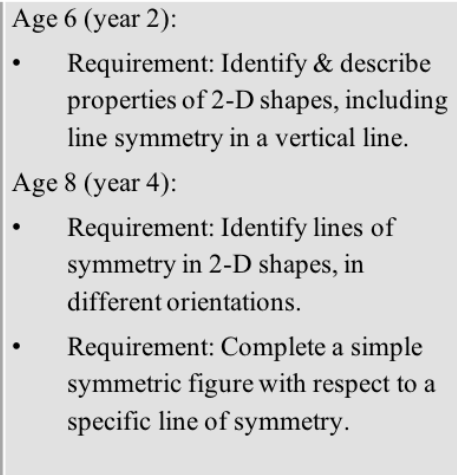 & $\begin{array}{l}\text { - Understand the concept, what } \\
\text { - Unmmetry means. } \\
\text { symmetry - becoming familiar } \\
\text { with different orientations of } \\
\text { lines of symmetry. } \\
\text { - Understand the points of } \\
\text { connection in a shape and how } \\
\text { they might map to a line of } \\
\text { symmetry. } \\
\text { - Perspective taking capability is } \\
\text { important. }\end{array}$ & $\begin{array}{l}\text { Considerations } \\
\text { - Which body actions, gestures or whole } \\
\text { body interactions enable representation of } \\
\text { shape? Which shapes? Collaboration? } \\
\text { - How to explore the shape to determine if } \\
\text { there is a line of symmetry (important that } \\
\text { shapes without can also be explored) and } \\
\text { where it might sit with respect to the } \\
\text { shape. } \\
\text { How to meaningfully augment the shape } \\
\text { with a chosen line of symmetry. } \\
\text { - How to feedback during exploration? }\end{array}$ \\
\hline
\end{tabular}

Figure 3. Example of an initial WeDraw pedagogical framework consideration: symmetry

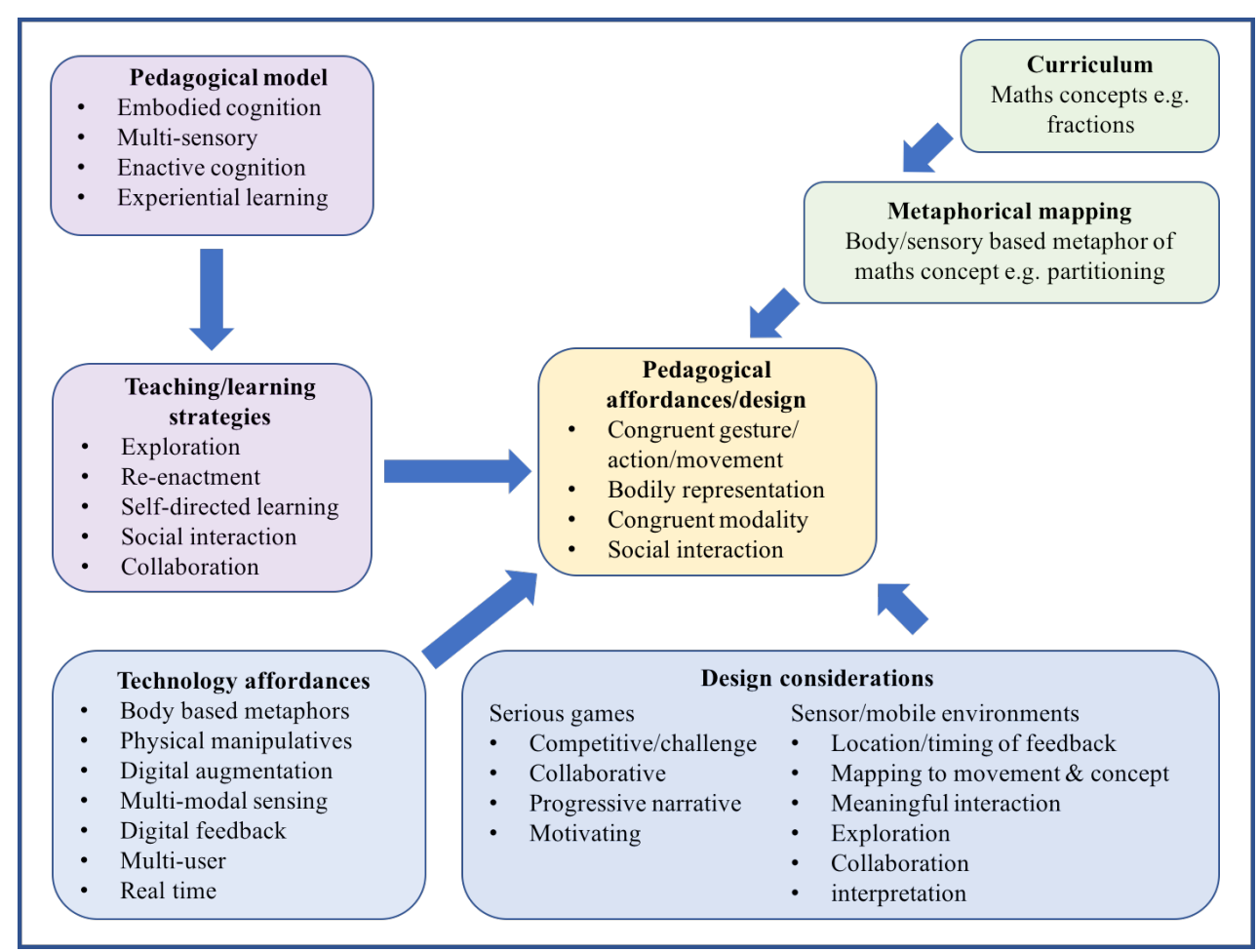

Figure 4. Initial Pedagogical Framework

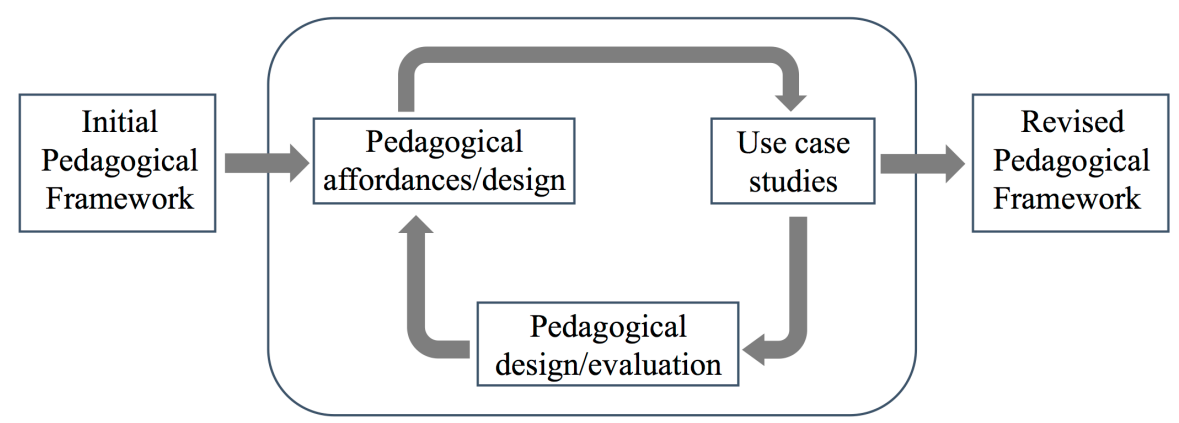

Figure 5. Process for pedagogical framework development 
For the WeDraw project, the pedagogical framework shown in Figure 4 will be incorporated into an iterative design process used to develop technology use cases for prototype games, as shown in

Figure 5. These will be evaluated, both at the conceptual stage with teachers, and in the form of technology prototypes that will be evaluated with the users (teachers and children). At each stage of evaluation, the pedagogical affordances will be reconsidered based on the results, whilst maintaining reference to the initial pedagogical framework. Studies will be designed to explore how children explore the pedagogical concepts, that will form part of the affordances/design stage, and inform the use cases. For example, designing simple games that encourage children to solve problems of symmetry together in pairs, in order to understand the language, gestures and body movement that are used by each age group. Since the ambition of WeDraw is to develop a series of multisensory serious games, these studies will inform the use of different sensory inputs (such as whole body movement) and feedback (e.g. haptic, visual, audio).

\section{CONCLUSION AND NEXT STEPS}

The aim of the pedagogical framework is to illustrate that the theory of learning (pedagogical underpinning) leads to consideration of instructional strategies that involve the 'body', through a multisensory serious games design, which is also informed by appropriate mathematical metaphors and technology design guidelines, in building meaningful connections between physical action and concepts in early years' mathematics. The framework will continue to be developed across the project with two key aims:

1. To develop the pedagogy driven design process to inform and extend the overall pedagogical framework.

2. To use the framework to identify detailed individual pedagogical affordances and design requirements for each mathematical concept, and serious games module, developed across the project. These will specify the kinds of actions/gestures, modes of augmentation and feedback, in relation to the mathematical concept/ metaphor and the pedagogical model, for each activity.

The workshop forum should provide opportunities for discussion around these initial ideas, that will support the ongoing development of a pedagogical framework for designing multisensory serious games to support the teaching and learning of young children's mathematics.

\section{ACKNOWLEDGMENTS}

This project has received funding from the European Union's Horizon 2020 Research and Innovation Programme under Grant Agreement No. 732391. The content of this publication is the sole responsibility of the authors. The European Commission or its services cannot be held responsible for any use that may be made of the information it contains.

\section{REFERENCES}

[1] Abrahamson, D. and Sánchez-García, R. 2016. Learning Is Moving in New Ways: The Ecological Dynamics of Mathematics Education. Journal of the Learning Sciences. 25, 2 (2016), 203-239.

[2] Abrahamson, D. and Trninic, D. 2011. Toward an embodied-interaction design framework for mathematical concepts. Proceedings of the 10th International Conference on Interaction Design and Children - IDC'I1 (Ann Arbor, Michigan, 2011), 1-10.

[3] Alibali, M.W. and Nathan, M.J. 2012. Embodiment in Mathematics Teaching and Learning: Evidence From Learners' and Teachers' Gestures. Journal of the Learning Sciences. 21, 2 (2012), 247-286.

[4] Almeida e Costa, F. and Mateus Rocha, L. 2005. Embodied and Situated Cognition. Artificial Life. 11, (2005), 5-11.

[5] Anderson, A.A. 2005. The community builder's approach to theory of change.

[6] Antle, A. 2007. The CTI framework: informing the design of tangible systems for children. Proceedings of the 1st international conference on Tangible and embedded interaction - TEI '07 (Baton Rouge, LA, 2007), 195-202.

[7] Barsalou, L.W. 2008. Grounded Cognition. Annual Review of Psychology. 59, (Jan. 2008), 617-645.

[8] Benford, S. et al. 2000. Designing storytelling technologies to encourage collaboration detween young children. Proceedings of the SIGCHI conference on Human factors in computing systems - CHI 'OO (New York, New York, USA, 2000), 556-563.

[9] Benton, L. et al. 2016. Building mathematical knowledge with programming: insights from the ScratchMaths project. Constructionism in Action 2016 (2016), 26-33.

[10] Chahine, I.C. 2013. The impact of using multiple modalities on students' acquisition of fractional knowledge: An international study in embodied mathematics across semiotic cultures. Journal of Mathematical Behavior. 32, 3 (2013), 434-449.

[11] Charsky, D. 2010. From Edutainment to Serious Games: A Change in the Use of Game Characteristics. Games and Culture. 5, 2 (2010), 177-198.

[12] Clark, A. and Chalmers, D. 1998. The Extended Mind. Analysis. 58, 1 (1998), 7-19.

[13] Cramer, E.S. and Antle, A.N. 2015. Button Matrix: How Tangible Interfaces Can Structure Physical Experiences for Learning. Proceedings of the Ninth International Conference on Tangible, Embedded, and Embodied Interaction TEI'15 (Stanford, CA, 2015), 301-304.

[14] Cuendet, S. et al. 2012. Tangible vs. virtual representations. Proceedings of the 7th Nordic Conference on Human-Computer Interaction Making Sense Through Design - NordiCHI '12 (Copenhagen, 2012), 99-108.

[15] Curzon, P. et al. 2009. Enthusing and inspiring with reusable kinaesthetic activities. Proceedings of the 14th annual ACM SIGCSE conference on Innovation and technology in computer science education - ITiCSE '09 (Paris, 2009), 94-98.

[16] Decety, J. and Grèzes, J. 2006. The power of simulation: Imagining one's own and other's behavior. Brain Research. 1079, 1 (2006), 4-14.

[17] Department for Education 2013. Mathematics programmes of study: key stages 1 and 2 National curriculum in England.

[18] Dourish, P. 2001. Where the Action Is: The Foundations of Embodied Interaction. MIT Press.

[19] Duffy, S. et al. 2017. WeDraw : using multisensory serious games to explore concepts in primary mathematics. Proceedings of the 13th International Conference on Technology in Mathematics Teaching - ICTMT 13 (Lyon, 2017), in press.

[20] Elia, I. et al. 2014. The role of gestures in making connections between space and shape aspects and their verbal representations in the early years: findings from a case study. Mathematics Education Research Journal. 26, 4 (2014), $735-761$

[21] Garbarini, F. and Adenzato, M. 2004. At the root of embodied cognition: Cognitive science meets neurophysiology. Brain and Cognition.

[22] Goldin-Meadow, S. et al. 2009. Gesturing Gives Children New Ideas About Math. Psychological Science. 20, 3 (2009), 267-272.

[23] Gori, M. 2015. Multisensory Integration and Calibration in Children and Adults with and without Sensory and Motor Disabilities. Multisensory Research. 28, 1 2 (Apr. 2015), 71-99.

[24] Gori, M. et al. 2008. Young Children Do Not Integrate Visual and Haptic Form Information. Current Biology. 18, 9 (May 2008), 694-698.

[25] Habib, M. et al. 2016. Music and Dyslexia: A New Musical Training Method to Improve Reading and Related Disorders. Frontiers in psychology. 7, 26 (2016).

[26] Heath, C. and Lehn, D. Vom 2008. Configuring "Interactivity": Enhancing Engagement in Science Centres and Museums. Social Studies of Science. 38, 1 (Feb. 2008), 63-91.

[27] Hohenwarter, M. and Fuchs, K. 2004. Combination of dynamic geometry, algebra and calculus in the software system GeoGebra. Computer algebra systems and dynamic geometry systems in mathematics teaching conference 2004 (2004). 
[28] Hornecker, E. et al. 2008. Collaboration and interference: Awareness with Mice or Touch Input. ACM 2008 Conference on Computer Supported Cooperative Work (CSCW'08) (San Diego, CA, 2008), 167-176.

[29] Hornecker, E. and Buur, J. 2006. Getting a grip on tangible interaction. Proceedings of the SIGCHI conference on Human Factors in computing systems - CHI '06. (2006), 437.

[30] Hornecker, E. and Dünser, A. 2009. Of pages and paddles: Children's expectations and mistaken interactions with physical-digital tools. Interacting with Computers. 21, 1-2 (Jan. 2009), 95-107.

[31] Hostetter, A.B. and Alibali, M.W. 2008. Visible embodiment: Gestures as simulated action. Psychonomic Bulletin \& Review. 15, 3 (2008), 495-514.

[32] Huizenga, J. et al. 2009. Mobile game-based learning in secondary education: engagement, motivation and learning in a mobile city game. Journal of Computer Assisted Learning. 25, 4 (2009), 332-344.

[33] Hutto, D.D. et al. 2015. The enactive roots of STEM: Rethinking educational design in mathematics. Educational Psychology Review. 27, 3 (2015), 371-389.

[34] Johnson, D.W. and Johnson, R.T. 1999. Learning together and alone: cooperative, competitive, and individualistic learning. Allyn and Bacon.

[35] Ke, F. and Grabowski, B. 2007. Gameplaying for maths learning: Cooperative or not? British Journal of Educational Technology. 38, 2 (Mar. 2007), 249-259.

[36] Kessell, A. and Tversky, B. 2011. Visualizing space, time, and agents: Production, performance, and preference. Cognitive Processing. 12, (2011), $43-$ 52.

[37] Kim, M. et al. 2011. Children's gestures and the embodied knowledge of geometry. International Journal of Science and Mathematics Education. 9, 1 (2011), 207-238.

[38] Klemmer, S.R. et al. 2006. How Bodies Matter: Five Themes for Interaction Design. Proceedings of the 6th ACM conference on Designing Interactive systems - DIS '06 (Pennsylvania, 2006), 140-149.

[39] Laanpere, M. et al. 2014. Pedagogy-driven Design Of Digital Learning Ecosystems. Computer Science and Information Systems. 11, 1 (2014), 419442 .

[40] Lakoff, G. and Núñez, R.E. 2000. Preface. Where mathematics comes from: How the embodied mind brings mathematics into being. Basic Books. XI-XVII.

[41] Ma, J.Y. 2017. Multi-Party, Whole-Body Interactions in Mathematical Activity. Cognition and Instruction. 8, April (2017), 1-24.

[42] Manches, A. and O'Malley, C. 2016. Cognition and Instruction The Effects of Physical Manipulatives on Children's Numerical Strategies. Cognition and Instruction. 34, 1 (2016), 27-50.

[43] Martin, T. and Schwartz, D.L. 2005. Physically Distributed Learning: Adapting and Reinterpreting Physical Environments in the Development of Fraction Concepts. Cognitive Science. 29, 4 (Jul. 2005), 587-625.

[44] Meluso, A. et al. 2012. Enhancing 5th graders' science content knowledge and self-efficacy through game-based learning. Computers \& Education. 59, 2 (Sep. 2012), 497-504

[45] Merleau-Ponty, M. 1962. Phenomenology of Perception. Routledge and Kegan Paul Ltd.

[46] Nakamura, J. and Csikszentmihalyi, M. 2002. The concept of flow. Handbook of Positive Psychology. Oxford University Press.

[47] Nemirovsky, R. et al. 2012. When the Classroom Floor Becomes the Complex Plane: Addition and Multiplication as Ways of Bodily Navigation. Journal of the Learning Sciences. 21, 2 (2012), 287-323.

[48] Nicolopoulou, A. 1993. Play, cognitive development, and the social world: Piaget, vygotsky, and beyond. Human Development. 36, 1 (1993), 1-23.

[49] Nunes, T. et al. 2009. Key understandings in mathematics learning. Nuffield Foundation.

[50] Park, Y. 2011. A Pedagogical Framework for Mobile Learning: Categorizing Educational Applications of Mobile Technologies into Four Types. International Review of Research in Open and Distance Learning. 12, 2 (2011).

[51] Piaget, J. 1972. The principles of genetic epistemology. Routledge and Kegan Paul Ltd.

[52] Prensky, M. 2005. Computer games and learning: Digital Game-Based Learning. Handbook of computer game studies. 18, (2005), 97-122.
[53] Price, S. 2008. A representation approach to conceptualizing tangible learning environments. Proceedings of the 2nd international conference on Tangible and embedded interaction TEI 08 (Bonn, Germany, 2008), 151-158.

[54] Price, S. et al. 2010. Action and representation in tangible systems: implications for design of learning interactions. Proceedings of the fourth international conference on Tangible, embedded, and embodied interaction - TEI '10 (New York, New York, USA, 2010), 145-152.

[55] Price, S. and Falcão, T.P. 2009. Designing for physical-digital correspondence in tangible learning environments. Proceedings of the 8th International Conference on Interaction Design and Children - IDC '09 (Como, Italy, 2009), 194-197.

[56] Radcliffe, D. 2008. A Pedagogy-Space-Technology (PST) Framework for Designing and Evaluating Learning Places. Proceedings of the Next Generation Learning Spaces 2008 Colloquium (Brisbane, 2008), 9-16.

[57] Ritterfeld, U. et al. 2009. Serious games: Mechanisms and effects. Routledge.

[58] Roschelle, J. and Pea, R. 2002. A walk on the WILD side: How wireless handhelds may change computer-supported collaborative learning. International Journal of Cognition and Technology. 1, 1 (Jan. 2002), 145-168.

[59] Sakr, M. et al. 2016. Mobile Experiences of Historical Place: A Multimodal Analysis of Emotional Engagement. Journal of the Learning Sciences. 25, 1 (Jan. 2016), 51-92.

[60] Sellar, S. and Cormack, P. 2007. Framing pedagogies: a review of frameworks and research designed to promote effective approaches to teaching and learning.

[61] Shaer, O. and Hornecker, E. 2009. Tangible User Interfaces: Past, Present, and Future Directions. Foundations and Trends in Human-Computer Interaction. 3, 1-2 (2009).

[62] Shaun Gallagher 2005. How the Body Shapes the Mind. Clarendon Press.

[63] Shoval, E. 2011. Using mindful movement in cooperative learning while learning about angles. Instructional Science. 39, 4 (2011), 453-466.

[64] Siegler, R.S. and Ramani, G.B. 2008. Playing linear numerical board games promotes low-income children's numerical development. Developmental Science. 11, 5 (Sep. 2008), 655-661.

[65] Smith, C.P. et al. 2014. Learning angles through movement: Critical actions for developing understanding in an embodied activity. Journal of Mathematical Behavior. 36, November 2016 (2014), 95-108.

[66] Smith, L. and Gasser, M. 2005. The Development of Embodied Cognition: Six Lessons from Babies. Artificial Life. 11, 1-2 (2005), 13-29.

[67] Starr-Glass, D. 2016. Participation in Online Distance Learning Environments: Proxy, Sign, or a Means to an End? Handbook of research on strategic management of interaction, presence, and participation in online courses. L. Kyei-Blankson et al., eds. IGI Global. 611.

[68] Suh, J. and Moyer, P.S. 2007. Developing students' representational fluency using virtual and physical algebra balances. Journal of Computers in Mathematics and Science Teaching. 26, 2 (2007), 155-173.

[69] Vygotsky, L.S. 1978. Mind in society : the development of higher psychological processes. Harvard University Press.

[70] Walkington, C. et al. 2012. Grounding Mathematical Justifications in Concrete Embodied Experience: The Link between Action and Cognition. The Annual meeting of the American Educational Research Association (Vancouver, 2012), $1-36$.

[71] Wiemers, M. et al. 2014. Spatial interferences in mental arithmetic: Evidence from the motion-arithmetic compatibility effect. The quarterly journal of experimental psychology. 67, 8 (Aug. 2014), 1557-1570.

[72] Wilson, M. 2002. Six views of embodied cognition. Psychonomic bulletin \& review. 9, 4 (Dec. 2002), 625-36.

[73] Winograd, T. and Flores, F. 1986. Understanding Computers and Cognition : A New Foundation for Design. Ablex Publishing Corporation.

[74] Young, M.F. et al. 2012. Our Princess Is in Another Castle: A Review of Trends in Serious Gaming for Education. Review of Educational Research. 82, 1 (2012), 61-89. 